ARTICLE

Received 18 May 2016 | Accepted 7 Jul 2016 | Published 6 Sep 2016

DOl: 10.1057/palcomms.2016.62

\title{
Listening between the lines: medieval and modern science
}

Giles Gasper ${ }^{1}$, Tom McLeish ${ }^{1}$ and Hannah E Smithson ${ }^{2}$

\begin{abstract}
In this article the investigators of the Ordered Universe project will reflect on how a diverse range of disciplinary perspectives essential for effective research into medieval science have been identified, acknowledged and absorbed into a genuinely interdisciplinary methodology. The project operates with a radical interdisciplinary composition bridging science and humanities in particular. How to translate what might be termed current academic practices and expectations between disciplines and between colleagues is a key issue. The article explores the practices of collaborative discussion, collaborative reading and collaborative writing. Central to these issues is the notion of the "atmosphere of enquiry": getting the best from disciplinary perspectives, respecting expertise and having the right to challenge disciplinary boundaries are integral elements within the process. Finally the experience of this project is set in the context of the wider discussion of what interdisciplinary research means. We discuss how the methods of the Ordered Universe might be used, by imitation or by analogy. This article is published as part of a collection on interdisciplinarity.
\end{abstract}

\footnotetext{
${ }^{1}$ Durham University, Durham, UK ${ }^{2}$ University of Oxford, Oxford, UK
} 
O ne of the fundamental tenets for effective research is encapsulated in a fragment attributed in the eighteenth century to the Greek stoic philosopher Epictetus (first/ early second century $\mathrm{AD}$ ). It was rendered in the wonderful English translation by Carter (1758: 499) as follows: "Nature hath given men one tongue but two ears, that we may hear from others twice as much as we speak". Listening involves sensory, perceptual and psycholinguistic human process, as well as provoking a wide range of metaphorical responses (Rost, 2002). ${ }^{2}$ Defining listening is a complex task: an invisible mental act with visible and audible consequences. No matter how difficult it is to define, however, effective listening is a prerequisite for collaborative research.

The present authors are only too conscious of the importance of listening in collaborative research, having experienced it most powerfully in the context of a rather unusual project. The Ordered Universe Research Project brings together a very wide range of scholarly disciplines from both sciences and humanities. ${ }^{3}$ The project's focus is a fresh, interdisciplinary, examination of the 13 scientific treatises on natural phenomena by the medieval polymath Robert Grosseteste (c.1170-1253). These treatises were written between the period c.1200 and about 1228. They cover a wide range of subjects: sound, the universe, time calculation, comets, the movement of the planets, the nature of space and place, the medieval elements, differences in geographical location, lines, angles, colour, light and the rainbow. The breadth of subject-matter and Grosseteste's own methods of investigation and interpretation are, in of themselves, challenging to elucidate. However, the ramifications of the project for that period's legacy on the way we think today, and for how we can work creatively between and among disciplines from the humanities and sciences, moving from respectful conversation to intense collaboration, make the project all the more radical and illuminating. It is a journey that has taken us from mutual interest in a treatise from $\mathrm{c}$. 1225 on the metaphysics of light, to new editions, new translations and new science published in leading scientific journals, and a series of creative collaborations with artists. What follows are reflections on the interdisciplinary nature of the project, how our practice has evolved, and the importance, and complexity, of listening across disciplines and time-periods.

Listening is a timely as well as an appropriate metaphor and practice on which to reflect for members of the Ordered Universe project. In November 2015, we completed our collaborative deliberations on the earliest of Grosseteste's treatises, the De generatione sonorum (On the Generation of Sounds), and the De liberalibus artibus (On the Liberal Arts), in which a preliminary version of Grosseteste's sound theories appears. With respect to the generation of sound, Grosseteste is concerned to explore a particular thesis. An object capable of making a sound (sonativum), when struck has its parts moved from their natural place; the nature and inclination of that sounding object tries to bring these parts back to their original position. However, in so doing, the parts move beyond that original position, and the repeated oscillating motion creates a sequence of alternate extension and contraction of the longitudinal and latitudinal diameters of these innermost parts. These movements set up a vibration which, Grosseteste states, is "evident to sight and touch". The vibration moves the air and thereby reaches the ear. The sensation of hearing is generated as a result. The treatise then advances this discussion to consider the phonetic application of the generation and perception of sound, using the example of vocal production relating to vowels.

It is the dislocation and perturbation from its initial form that allows the object to create sound, and it is the movement provoked by that dislocation and perturbation that enables the sound to be perceived. This is analogous to aspects of the interdisciplinary practice in which we engage. All participants have the capacity to interpret the text under scrutiny from within their own disciplinary fields. These interpretations might be more, or less, successful. It is the dislocation of that disciplinary focus and the perturbation of, and movement from, natural scholarly inclinations that occurs in discussion from multiple perspectives, that gives voice to the project. Simply having voices in a room is only the beginning of the process. How the different perspectives are listened to forms the essential part of the research project.

These two treatises encapsulate the research challenges faced by the Ordered Universe team. There are demanding textual concerns, complex questions connected to translation, and intellectual puzzles in tracing Grosseteste's own reading, his exploration of natural phenomena and their understanding. Since the natural phenomena, such as sound, rainbows and colour remain a constant between the thirteenth century and the modern-day, we are able to use modern scientific understanding to tease out what Grosseteste in his own cultural context was attempting to describe.

The treatise on sounds, for example, reveals Grosseteste's particular talent for uniting disparate sources of information, book-learned and observed, into a coherent argument. Augustine, Isidore, Priscian and Aristotle are all marshalled in his analysis of both sound and hearing, and their phonetic application. There are also physical, mathematical and psychological aspects to the treatise. The physical acoustics of objects that might have displayed the biaxial motion that Grosseteste describes can be explored, including consideration of Poisson's ratio, mathematical analysis of the combined motions for vowel shapes can be carried out, and the psychological association of sound with letter shape can be examined.

Grosseteste took a critical approach to his authoritative sources, but his thinking is characterized nonetheless by a strong instinct to stress the harmony of explanations concerning natural phenomena. He possessed considerable powers of scientific imagination and was unafraid, also, to change his mind in the face of new information. In the 1220s, Grosseteste dealt again with sound and the theory expounded in On the Generation of Sounds in his Commentary on the Posterior Analytics by Aristotle. However, though quoting from his earlier treatise, he now associates sound with light, and explores sound generation as part of his wider, and original, theme of the embodiment of light as the dominant motive force in the universe, that which creates movement, natural phenomena such as colour and sensory perception (Panti, 1998).

The Ordered Universe project began its investigations of Grosseteste's scientific treatises by concentrating on the short treatise, only some 400 words, On Colour (Dinkova-Bruun et al., 2013). The formation of our first questions as to how to approach the text created an interdisciplinary response which has continued to shape the project ever since. Although short, the concentration of ideas in the treatise and its mathematically ordered grammar, taut prose and oblique references to Aristotelian and Arabic thought have puzzled scholars since its last edition, made by the German scholar Ludwig Baur in 1912 (Baur, 1912). ${ }^{4}$ Baur's edition was a remarkable achievement in its day, and instigated the rising interest in the twentieth century in Grosseteste's scientific works. The edition is showing its age and limitations, however. Baur was familiar with fewer than half of the manuscripts currently identified as containing the scientific works, and, on occasion, those he used were late copies in the transmission, which preserved a higher percentage of copying errors. This became evident in our treatment of On Colour and the concomitant need for new editions of the other scientific works. ${ }^{5}$ 
While the treatise on colour might not contain equations, the logic of the treatise is clearly mathematical: a listing of the qualities of colour leads to a subtle counting argument, a move from discrete to continuous gradations of colour and an intriguing reference to things one could prove per experimentum [through experiment or experience]. The treatise is written in Latin (hence the need for Latinists). It exists in 11 manuscripts scattered about European libraries and of uncertain provenance (signalling a need for palaeographers). It draws on early medieval Arabic philosophy and mounts an implied critique of Aristotle (the specialisms of historians of philosophy and Arabists). It refers to the human perception of colour in detail (hence the need for colour vision psychologists). It invokes enumerative combinatrics (thereby raising a need for mathematical physicists).

This represents only the bare minimum of interdisciplinary mix. Later we discovered that the colour theory could only be completely understood when compared to Grosseteste's related treatise On the Rainbow. To fully understand, the treatise required a detailed knowledge of meteorology (so an atmospheric scientist), physical optics (more than one experimental physicist/ engineer) and atmospheric absorption of sunlight (that needed an astronomer). This amounts to a considerable collection of disciplinary perspectives. All are required to elucidate Grosseteste's extraordinary textual legacy and on the complex natural phenomena he discusses. The topics that he investigates are complex, and our current understanding of them draws on all of these (now fragmented) disciplines. To leverage modern understanding both of Grosseteste's world and the phenomena, involves a significant number of scholars. The complex nature of his scientific texts, the precision of linguistic expression, and their computational virtuosity present intellectual challenges that can only be addressed with an interdisciplinary approach.

\section{Background to Grosseteste: scientific scope}

Grosseteste was one of the first generations of western scholars to engage with Aristotle's natural philosophy by means of translations from Greek into Latin. This process, which started in the early twelfth century continued throughout the thirteenth. Where Aristotelian works themselves were translated predominantly from Greek, western scholars also engaged with the rich and diverse tradition of commentary on these works by Islamic scholars. Figures such as Al-Farabi (872-950), Ibn Sina (9801037) and Ibn Rushd (1126-1198) became familiar in the Christian West under their Latinized names (in the case of those above: Alpharabius, Avicenna and Averroes). By the end of the thirteenth century as Bartlett ([1982] 2006: 104) puts it "the entire scientific knowledge of two cultures had become available through the translation movement". Translation of Jewish philosophical reflection, such as the Fons vitae [Fount of Life] by Iberian author Solomon ibn Gabriol (Avicebron) also played their part in the astonishing broadening of the intellectual inheritance of the medieval West.

Grosseteste's treatises on natural phenomena ride on the crest of this new knowledge. The impact of new reading can be seen within his own writings. Those of the 1220 s show the influence of Averroes's Great Commentary on Aristotle's Physics. The range of textual sources, which Grosseteste seemingly acquired was extraordinary. His treatise On Light, which deals essentially with the problem of how body is generated (taking as its ultimate subject the greatest of all bodies, the universe), is a veritable homage to ancient and early medieval cosmology, Classical, Christian and Islamic. This capacity to absorb new and old learning, and in quantity, carried through to his later theological writings. As McEvoy (2000: 106) remarks, when it came to the composition of Grosseteste's commentary on the 6 days of
Creation in Genesis, "The desk at which he worked must have been huge", a striking image to conjure the range of biblical, ancient and medieval texts of which he displays knowledge. This commentary, the Hexaemeron, written up in the 1230s, makes frequent use of Grosseteste's earlier scientific learning.

Although extensive and carried out with a complex and sophisticated frame of reference, Grosseteste's reading was never slavish. Independent lines of thought are traced, his authorities tested, and, where appropriate, shown to be lacking. Grosseteste also uses, powerfully, modes of analysis and explanation that draw on geometric mathematics. In the treatise On Light, for example, the infinite multiplication of light and matter, which underpins the creation of the spheres of the universe, is linked to the mathematical notion that finite, numerical ratios result from suitably defined quotients of infinite series. The treatise $\mathrm{On}$ Colour defines colour as light embodied in a suitable medium, with three bi-polar qualities, two of light and one of the medium (how the medium is to be defined is discussed below) (Smithson et al., 2012: 346-352; Dinkova-Bruun et al., 2013: 16-19). These combinations of light (clara or obscura; multa or pauca) and of the medium (purum or impurm) imply a mathematically threedimensional conceptual frame for the perception of colour. The treatise goes on to explore how these combinations, moving between the two extremes of blackness and whiteness, produce a middle-space in which all possible colours exist.

Grosseteste returns to his theory of colour in his last scientific treatise that On the Rainbow. This treatise dwells especially with optics, including Grosseteste's observation and description of the law of refraction, as well as his application of colour theory to the differences of colour within and between natural rainbows (Smithson et al., 2014a,b). ${ }^{6}$ By applying modern science of geometrical optics and atmospheric absorption, we have been able to evaluate Grosseteste's claim that colour space is effectively spanned by all possible rainbows. In consequence, by so looking at rainbows though his eyes, as it were, we have been able to map the colours in his work on the rainbow onto the ambiguous terms employed in On Colour. The effectiveness of the interplay between scientific and textual analysis is made clear in this example.

The extent to which Grosseteste based any of his treatises on natural phenomena on observation, or even experiment, is debatable. Crombie (1953) famously associated him with the origins of experimental science. The boldness of this claim was criticized almost instantly, and heavily (Koyré, 1957; Eastwood, 1968). It is the case that Grosseteste's treatises and his commentary on the Posterior Analytics recount ancient experimenta. In the latter work he references the famous investigation of the relation between ingestion of scammony (a gum-like resin from the root of bindweed native to the eastern Mediterranean) and the production of bile in the human body. Aristotle recounts this, Grosseteste comments, noting that reason is thereby converted by experience: more scammony, more bile (Grosseteste, 1981). While Grosseteste in this example knew what a non-mathematical experiment is, that is, the observation of two concomitant events with a causal and empirically testable relationship, there is no evidence that he carried it out in practice. Similarly in the treatise On the Rainbow Grosseteste reports an experiment, or statement of principle, from the Pseudo-Euclid, De speculis, Concerning mirrors: "if something is placed in a vessel [container], which is placed at a distance, so that the thing placed in it is no longer seen, this thing will become visible if water is poured in". 7 Again, whether Grosseteste himself did this is not, strictly speaking, established by the internal evidence of the treatise. Later experiment may be implied by an early fourteenthcentury copy of the treatise, now held in Merton College, University of Oxford, which identifies the "something" placed in 
the vessel as a coin (denarius) (University of Oxford, Merton College, Manuscript 306, f 118ra). ${ }^{8}$

While at one level Grosseteste's works give us no more than a verdict of non-proven on the question of empiricism, this does not, of course, imply that he might not have experimented. Quite how the Latin word "experimentum" is to be translated is both the key to the problem, and the problem itself. It is perfectly reasonably translated as both "experiment" and "experience". Both of these apply to scientific practice, and the interplay between observation on the one hand, the instincts, knowledge and intuition of the observer, and the construction of investigative parameters with which to measure and test a given set of circumstances on the other. Indeed, the same ambivalence is retained in the modern French use of "faire une expérience" to denote "experiment" (Wooton, 2015: 312-313). ${ }^{9}$ In the working out of quite what Grosseteste means in his discussions of natural phenomena, modern scientists provide an important perspective. This is the more so since physical phenomena are the same today as they were in the thirteenth century and in this sense too, modern science, especially in its investigation of how human beings process sensory information about these phenomena, helps considerably in the elucidation of textual description.

The range, depth and complexity of Grosseteste's scientific treatises make their investigation by an interdisciplinary team appropriate. Bringing together the approaches of multiple disciplines allows a fuller consideration of the implications of the texts and their meaning, with interdisciplinary results. Grosseteste's scientific thought is peculiarly well suited to such an exercise. Although his thought evolves and develops, as he encountered and embraced new sources of knowledge and inspiration, the treatises remain relatively short and focused on discrete questions. For example, the Posterior Analytics of Aristotle on which he commented at length in the mid-1220s, a commentary that was still taught and consulted into the fourteenth century, brought substantial change to Grosseteste's articulation of what science was, with specific impact on his notion of the centrality of light in the universe. The intellectual changes of direction and emphasis are all subordinate to his central enquiry into the world around him and how it should be understood and perceived.

\section{Grosseteste background: life and career}

Access to a wider research team is extremely helpful in another key area as well. It is not uncommon for the lives of medieval thinkers to be rather less well documented than the survival of their works. Grosseteste is no exception. After his appointment as bishop of Lincoln in 1235 documentation for his activities is prodigious, including a letter collection and an extensive series of administrative material. Lincoln diocese in the thirteenth century stretched from the Humber to the Thames, across eight counties, organized into eight archdeaconries, with 77 rural deans and over 2000 parishes (Southern, 1992: 258). Grosseteste was an active and reforming bishop whose episcopal exertions were recorded in detail (Hoskins, 2015). Before this period of his life, however, evidence of even his whereabouts is far patchier.

Born probably in Suffolk in around 1170/75, Grosseteste first appears in the historical record at the Cathedral school of Lincoln in the early 1190s. From 1195 to 1198 he served in the household of the bishop of Hereford, William de Vere. On the bishop's death, the household dissolved, and Grosseteste's movements again become harder to chart. He was involved in the prosecution of legal cases in Herefordshire and Shropshire in the first two decades of the thirteenth century, and was appointed Rector of Abbotsley in Lincoln diocese in 1225. In about 1227, he became lector in theology to the new Franciscan community at Oxford
(Southern, 1992: 63-70). For the period in which he composed his scientific writings, c.1200-c.1228, there are, then, few waypoints from which to construct his career.

It is likely that he spent at least part of that time at the University of Paris. From its origins in the twelfth century, the University had grown and evolved into the leading institution of higher education in Western Europe, especially for theology by the time of Grosseteste's earliest writings. Oxford was not far behind in institutional development, and it is probable that Grosseteste spent time there as well (Goering, 1995). This would be consistent with the general pattern of education for the period. An alternative model, advanced by Sir Richard Southern, places Grosseteste in an English context, and emphasizes his continuity with a longer history of interest in science and nature among English centres of learning throughout the twelfth century (Southern, 1992: xviii-lxvi and 49-62).

The two versions of Grosseteste's career are not incompatible. Where earlier scholarly debates on his career turn on the chronology of his writings and the question whether some among his scientific writings pre-date or post-date his theological writing, the modern consensus is to place his scientific writings first. This conforms to the normal pattern of medieval university education (Colish, 1997). In this the student first trained in the Liberal Arts, then in Theology, Medicine or Law. The Liberal Arts curriculum has its roots within Ancient Greek and Roman pedagogical schema, and was conceptualized as a combination of the Trivium: Grammar, Rhetoric and Logic, and the Quadrivium, or the mathematical arts: Astronomy, Arithmetic, Geometry and Music. In practice other subjects were taught within the Arts Faculty, and the standard texts changed throughout the twelfth and thirteenth century. Grosseteste's scientific works and interests may, then, be placed within the scope of the Quadrivium. This is corroborated by his possible pupil Roger Bacon (1214/20-1292) who, in the later thirteenth century, lauded Grosseteste for his mathematical skill (Bacon, 1897, vol. i.: 108).

The lack of clear chronology poses considerable challenges to the elucidation of Grosseteste's scientific treatises. To identify the sequence of the treatises is a delicate balance between internal evidence of how his ideas progress, the use of new sources and comparison with contemporaries. How Arabic and Greek works were transmitted to Latin scholars, when they became available, who used them and why, is an important aspect in this process. The availability of other, older texts is a crucial question incorporating issues of book-culture, copying and libraryholdings. While these challenges are in no way unique to Grosseteste, they have to be addressed in any attempt to understand better his world-view, and the part played within that of his scientific interests.

From issues of manuscript reading and editing, contextual information, chronology, to those of content, reading Grosseteste's scientific works demand high-level skills and expertise. A wide range of scholarly disciplines are necessary and the interdisciplinary engagement is far more subtle than simply putting together "humanities" experts and "scientists". The Ordered Universe research team identifies specific, as well as general expertise, from codicology to Arabic science, medieval philosophy to modern cosmology, medieval history and theology to modern vision science and physics, medieval literature to engineering and mathematics.

\section{Practice: collaborative reading}

With a significant number of participants, and a diversity of backgrounds, we have developed a number of working practices, which, when taken together, point towards an iterative methodology of collective engagement. Both practice and reflection 
dwell with the relationships among individuals, their background, training, interests and encounter with Grosseteste's thought, the relationships among individuals in the research group and the different tasks that need to be carried out as a group: reading, oral discussion, modelling, coding and analysis, calculating, mathematical interpretation, finding and incorporating relevant data (such as solar spectra in the work on rainbows), and writing. We did not embark upon the project, which started in 2010, with an explicit theory of interdisciplinarity, and we continue to develop the project's interactions from its intellectual (and administrative) requirements. To this extent the interdisciplinary form is a product of the function of interactive research.

The most obvious disciplinary distinction within the research group is that between humanities and science. Without entering into a discussion of the two cultures, our experience has been that distinctive differences have gradually moved into the background as the project has advanced (Snow, 1959). ${ }^{10}$ Some clear distinctions remain: an instinctive movement towards mathematical or linguistic expression, a tendency towards visual and diagrammatic evidence on the part of scientists, practices of collaborative writing more easily adopted publicly by scientists, practices of source criticism and historiographical detail more commonly adopted by humanities experts. All of that said, these distinctions neither pertain in their totality to individuals nor are distinctive practices among science and humanity scholars to be ignored. A philosophical approach to a medieval thinker can be quite as unfamiliar, alien and distinct to an historical approach, as computational cosmology to organic chemistry. By foregrounding the task of interpreting Grosseteste's treatises, disciplinary focus becomes the tool and not the master for cross-cutting dialogue.

At a broader and deeper level, the relationship between disciplinary and interdisciplinary research is of profound, and defining significance to the Ordered Universe. Our research outputs, for example, are interdisciplinary: they distil the insights from all contributors, and are shaped to allow the reader to follow the text and discussion from the different points of view involved. On Colour was co-written by a medieval historian, a medieval linguist, a palaeographer and medieval Latinist, a medieval philosopher, a physicist and a colour vision specialist. While our disciplinary identities are not insisted upon at the expense of our individual and shared interests in Grosseteste and his treatises, they do remain integral elements in how the research is carried out. Nevertheless it is, ultimately, the focus on the treatise at hand that governs the attitudes and responses of the participants.

The collaborative nature of the project, and the centrality of Grosseteste's treatises are given physical instantiation in our main, collective, research activity. The project works through a series of research symposia, in what might be conceived of as classic humanities research. The establishment, translation and interpretation of the text is enriched by the perspectives and analysis of all around the table. It is this process of collective translation and textual elucidation that creates the environment for genuinely interdisciplinary outputs.

Collaborative reading is the foundation of the project. For a given symposium the palaeographer and Latinist will have prepared, in consultation with other medievalists within the team, a draft edition from the various manuscripts (with a list of Latin variants) together with a preliminary translation. We then read the treatise together, word by word, line by line, paragraph by paragraph. One member of the group acts as narrator and reads aloud the text of the English translation. The oral experience is an important one, allowing comparison to the Latin edition and a pace suitable for discussion and questions. Given the oral nature of medieval education there is some sense too in experiencing the text in, however, attenuated a way, in the medium for which it was principally designed. In this process the scholarly apparatus required to understand the text is the same for all participants. The scientists are not spared the details of the text, languages and historical context, nor the humanities scholars the discussions on the geometrical or combinatorial logic implied by the text, or the questions of what natural phenomena might have been in the perception and mind of the writer.

The act of translation within the group context becomes a highly interdisciplinary and non-linear practice itself. This is necessary to deal with the "Catch-22" problem that on the one hand it is not possible to translate the texts properly without knowing their mathematical and physical meaning and on the other it is hard to identify the mathematical and physical meaning without some sort of translation. This conundrum is resolved by iteration. A first pass of the literal translation often reveals sections where the meaning is far from clear, but in mutual struggling with the text a plausible rendering among the alternatives eventually surfaces. In the case of descriptions of natural phenomena, physical processes or geometrical patterns, the mathematical logic of Grosseteste's discussion is often central to teasing out the meaning of the text. The essential ingredient in our working practice is to engage together. There is never a clear boundary between a philological, philosophical or contextual discussion and mathematical reasoning or discussion of ray optics. Scientists need to feel free to question accepted translations and to suggest new ones. Humanities scholars need to know that they are welcome to challenge the kinematic interpretations or optical references and speculation advanced by the scientists.

Listening takes place in many different modes for the research group within the context of collaborative reading, both as individuals and collectively. Some of these modes will overlap, others will appear to be less closely related. Michael Rost's observations on the four orientations of listening are a helpful way to reflect on these processes (Rost, 2002: 2-3). ${ }^{11}$ First, receptive listening (receiving what the speaker actually says), which involves decoding what the speaker means; second, constructive listening (constructing and representing meaning), which involves the reframing of the speaker's message to a conceptual framework with which the listener is familiar, and noticing what has not been said; third, collaborative listening (negotiating meaning with the speaker and responding), which involves sharing information, signalling where ideas are clear and less clear in an inter-personal context; fourth, transformative listening (creating meaning through involvement, imagination and empathy), which involves imagining possible worlds for the speaker's meaning, entering the flow created by the convergence of different media, and completing the process of communication.

Every participant around the table, and we number typically between 18 and 30 in a collaborative reading session, would recognize these patterns of listening. Listening between disciplines involves a series of translations and we have many examples of this activity within the collaboration. These range from matters of terminology, to more technical issues. Of the former some scientists refer to "groups", some to "labs", as collections of people: confusing if "lab" is understood as a physical entity. Reference to primary and secondary sources by historians was also the occasion for misunderstanding. The distinction between sources contemporary to the period under scrutiny (primary) and subsequent scholarly reflection (secondary) could be seen as promoting a hierarchy of material of greater or lesser importance. Abbreviations can cause problems as well: an RGB cube is easily referred to, that it stands for red-green-blue was not always immediately apparent.

As well as learning to listen to each other the research group has learnt also to listen to the past. All of the same issues of 
terminology arise, this time from Latin and at a period when Latin was still a living and developing language. Words with different modern meanings provide complex issues of translation. In work on the treatise On Light, Grosseteste employs a lot of physical vocabulary, including the word moles. A natural translation would be "mass", but this presents issues of concerning modern specific and different, scientific connotations. Another case is the perspicuum, which Grosseteste describes in the beginning of the treatise On Colour: "Color est lux incorporata perspicuo" (Dinkova-Bruun et al., 2013: 17). "Colour is light incorporated in a perspicuum". Quite what perspciuum means here is intriguing: early fourteenth-century references indicate "lens" as a plausible translation. However, earlier usage does not have the same precision, making "transparent medium" a reasonable English rendition for the period of the text. The word-choice here raises all sorts of scientific possibilities. It would be quite possible to phrase the translation to give the impression that Grosseteste had a notion of splitting light using a prism some 400 years before Newton (1669; Newton Project, 2008-present). This would be quite wrong linguistically, as well as historically, even though Grosseteste in his treatise On the Rainbow, written about 5 years later, demonstrated his knowledge of refraction. It was this same treatise that helped to confirm the research team's collective decision to translate perspicuum as "diaphanous medium". Grosseteste repeats his remarks on colour as part of his rainbow treatise, using his own theory to explain the differences in colour within and between natural rainbows. Five years on, however, Grosseteste's reading of Averroes caused him to substitute perspicuum with the word diafanum (Giovani, 2013). Our collective movement towards "diaphonous medium" mirrored Grosseteste's own thought, which encouraged confidence in the faithfulness of the rendering.

Learning to appreciate the fragility of the past has been a key part in the evolution of Ordered Universe practice. The chances that lead to the survival of manuscripts of Grosseteste's works and their state of preservation are worth emphasizing. The scientific works seem to have been compiled in collections (not always with the same contents) from the later thirteenth century, as well as surviving independently. Survival rates differ. For the treatise $O n$ the Sphere there are over 50 extant manuscripts, testament to the treatise's purpose as an introduction to astronomy. Conversely, On the Liberal Arts survives in only six manuscripts, mostly from later in the Middle Ages. Some treatises, such as those in a volume, which formed part of the late seventeenth century Cotton Library, were fortunate to survive at all. A fire on 23 October 1731 did immense damage to the collection, the physical traces of which are apparent on a copy of On Colour, which remains charred and disfigured to this day.

The issues connected to how the standard, critical edition of the text is put together are important in this context also (Walsh, 2010). How the transmission occurred from the author's original (if indeed there was one since many medieval school's texts survive from student notes) to surviving manuscripts is difficult to trace. The process is one in which errors can accumulate. As an example, in Baur's edition of the treatise On Colour we find the statement the $7+7=9$. Clearly this is not true. Tracking what had happened between the earliest surviving manuscripts form the thirteenth century, to those from the fourteenth and finally the fifteenth century, resolved the issue. An Arabic numeral 14 had been taken for a Roman numeral IX (the medieval habit in writing Arabic " $4 \mathrm{~s}$ " was to tilt them to the left), which had been turned into the prose "novem" "nine". Hence, $7+7=9$.

At the same time as appreciating the slender framework on which our experience of the past depends, learning to listen to the past also involves an appreciation of the sophistication of the intellectual achievements of the past. This is a more difficult act in which to engage than might at first be thought. Especially for scholars of the modern period, the linear narratives of human progress are not easy to abjure. ${ }^{12}$ Intellectual progress makes autobiographical sense: I know more now than I did when a child. Indeed the accidental (or purposeful) patronizing of past thinkers as "childlike" in their knowledge is quite common. The challenging task of taking the past seriously, and a past thinker as an intellectual equal, or superior, has been something at which the research group has worked hard.

In this exercise Grosseteste's personal qualities are helpful. $\mathrm{He}$ does seem to have been regarded by contemporaries as a peculiarly adept and gifted man, expert at everything to which he turned his mind. According to Bacon (1859: 472), "Only lord Robert, on account of the longitude of his life and the wonderful methods he used, knew more than other men the sciences that the Greeks and the Hebrews did not know". The close association with the logic and premises of medieval scientific thought provides an antidote to the arrogant presumption that our current world-view is "right". A twenty-ninth century scientist may well view our current theories with the same condescension as many contemporary scientists view thirteenth century models.

There is a reciprocal challenge for the medievalists in the team. We can present Grosseteste, as far as we are able, in the context of his own religious, intellectual and material culture. To engage with modern science readings of his thought is to encounter an approach which is all too easy to write off as anachronistic. The apparent three-dimensional scheme within Grosseteste's colour theory naturally invites reflection on and comparison to modern understanding of colour perception (Smithson, 2015). Grosseteste's description of the universe beginning with a single point of light expanding instantaneously into the shape of a sphere, calls to mind modern conceptions of the first stages of the universe and its popularization as the "big bang" and the significance of light within this process. Were any of the team to suggest that Grosseteste anticipated quantum mechanics, or had prescient knowledge of ocular physiology then the charge of anachronism would be duly levelled, and justly. However, for a scientist to start a response to a complex text with a modern parallel is often a very stimulating way to get to the bottom of a passage whose meaning is not clear. A disciplinary start to addressing a problem ends in an interdisciplinary discussion and solution. Grosseteste is not interpreted here with any anachronism, least of all scientific. The interpretative tools of humanities and scientific disciplines are used together to bring the text to life in all of its dimensions.

We have also, as a team, come to appreciate that analysis of texts that purport to explain natural phenomena is enhanced by considering the phenomena as well as the author. An eye or a rainbow is the same in the thirteenth as the twenty-first century. This is a further area in which careful explanation of the circumstances in which these phenomena occur is crucial. In some cases, the experiences Grosseteste describes may not match those of the modern reader. For a modern city dweller, it is not clear that the night sky is something with which everyone would be familiar, as Grosseteste's contemporaries would have been. This may seem obvious but a disciplinary background in medieval history might not, automatically, presuppose that knowledge of this fact would be included in an analysis of Grosseteste's corpus of scientific texts. Different strands in our current education and academic paths may change the properties of the natural world with which we are familiar, and which we would emphasize in an interpretation of textual material. The reverse applies equally pertinently. Sometimes the accepted wisdom of a particular explanation can prevent us from looking properly. Thirteenth century reflection on natural phenomena is no less valid, in this sense, than that of the twenty-first. Applying 
these insights appropriately is another answer to the charge of anachronism.

\section{Practice: lessons from collaborative listening}

Learning to listen to each other's reactions to the texts, and not writing them off hastily has been the most taxing, but most rewarding element of the project. It makes us all question our own responses, and consider the breadth and significance of our own inquiries. In this way the project exemplifies what Thompson (2005: 8) calls "deftly balanced coming together of things that are generally considered parts of different ontological orders". Our experiences of the Ordered Universe project and developing ways of working in collaboration have allowed us to distil some essential practices that reflect and inflect aspects of interdisciplinary research practice. To explain a little further:

The importance of open and honest questions. It is extremely important to counter the perfectly normal concerns among established and early-career academics of appearing uninformed, poorly read or otherwise in the dark on the issues under discussion. Nothing gives away ignorance with more direct transparency that a public question about something that everyone else surely knows. However, no-one enters a project requiring participation of at least three disciplines with any chance of possessing more than a superficial acquaintance of the practices and subject-matters outside their primary area. Mutually recommended reading can help to get the team started, but without getting those questions out into the open the vital cross-disciplinary learning will never take place. Our experience had been that participants are made to feel very much more comfortable with the permission, and encouragement to be open and honest in their questions. Such team work together with its mutual and continuous learning and didactic functions has been identified repeatedly as a characteristic of interdisciplinary working. This was highlighted recently, for example, in a research paper emerging from the UK Academy of Medical Sciences Team Science report (Gewin, 2015).

Trespassers will be welcomed. Interdisciplinary projects can sometimes be imagined as occasions at which each participant provides expertise from their own background, but not beyond it, carefully policed by the project leaders. While disciplinary perspectives reflect our training, tastes and interests, it is important that they do not impede the intellectual confidence to range into new intellectual spheres. For the Ordered Universe to work, we need the humanities scholars to venture scientific ideas from their fresh perspectives. The scientists must feel welcome to suggest fresh translations of the Latin, informed by the mathematical or geometrical insights they bring to the text. It is the response to academic trespassing that generates the freshest thinking. A question asked from a non-specialist, though not non-expert, base, if listened to properly, will frequently generate thoughtful reflection that provokes more and deeper questions. The language of trespass takes us into the much-explored simile of territory in the literature on interdisciplinarity, which draws on the deeper root metaphor of disciplinarity as landscape or geographical feature. Our experience challenges the recommendation, sometimes voiced, that the disciplinary boundaries be carefully identified and policed before and during collaboration. So Thomas Osborne (2013) argues for the inherent recognition of disciplinarity as a pre-condition for interdisciplinarity. H. Bauer (1990) goes further, holding the necessary negotiation of "academic turf" as a prerequisite of collaboration. Yet there have been other articulations of the idea of territory. Nicholas Lash (1996: 112-131), in a plea for the recognition of academic unity wrote movingly of the need for the research community to realize that "we trample in each other's territory, sing each other's songs, whether we want to or not". Callard and Fitzgerald (2015) have argued for much more complex, nuanced and "topological" discourse of relation between disciplinary spaces than the planar mapping of territories, bringing further dimension to the root metaphor. We suggest that our experience of welcome trespass represents the first step towards such breaking, re-connecting and merging of disciplinary spaces, and one that is immediately powerful.

An environment for learning. A consequence of the disciplinary trespassing on which the vitality of the discussion depends is that we all strive to know as much as possible of the territory into which we wander. Here the role of interdisciplinary translation comes to the fore. We will never become experts in each other's disciplines, but we must learn enough to understand the languages, concepts and a coarse-grained understanding of our knowledge-worlds. ${ }^{13}$ Trespassing in total darkness is fruitless, but more than this, the interdisciplinary work of the symposia stands as a reminder that all participants enter and leave as students. We learn together, from each other, about our own disciplines and our own shibboleths. Disciplinary pride, passion and excitement are essential in this arena. The collaboration depends on credible experts in their own field whose enthusiasm about it is infectious. This leads to a culture within the group that valorises sharing, educating and inspiring. If listened to properly, the process is selffuelling. There is nothing more rewarding than working with an attentive audience or with expert teacher. Etymologically, and logically, at the heart of the notion of interdisciplinarity lies the activity of mutual, didactic, disciplining (McLeish and Poon, 2001). Furthermore, the very presence of the embedded process of mutual teaching and learning supports the active value of "academic humility" identified as an element of the successful research team by a UK working group of funders and researchers aimed at creating an evaluative framework for interdisciplinary research (McLeish and Strang, 2015).

Focus matters. Conversation between our different subjects alone does not sustain an interdisciplinary discourse. An object on which to focus concentration is equally necessary. ${ }^{14}$ For the Ordered Universe project the particular treatise by Grosseteste under scrutiny provides this focal point. It is in front of all of us continually and provides the start and end point for discussion, however, widely it roams in between (into the deeper background of the sources, back-tracing of a philosophical concept, or the physics of secondary rainbows). This point of focus for interdisciplinary analysis is also vital in creating a coherent community from the participants engaged in collaboration. In our case the elucidation of Grosseteste's texts provide an important, and disciplined, framework for privileged trespassing. Other interdisciplinary projects have noticed the pivotal nature of materiality, the import of materials (as well as knowledge, research questions and methodologies) from the participating disciplines, in generating a mutual focus (Woods, 2015).

Collaboration, co-location and community. The common point of focus also breaks a recurring pattern for interdisciplinary projects, namely the organization of work packages. These are generally under the responsibility of different participants, and subject to their own methodologies. Time together is then spent progressreporting, but not engaging together at core of the project, allowing the division of subsequent labour to flow from collective reading. To work in this way does, of course, take a great deal of time. Carving out days together for the readings and discussions has been expensive, but it is the generator of the project. Every step needs every voice, and every voice needs to be listened to. The social generation of knowledge, especially within interdisciplinary research, has been frequently cited as a prerequisite of flourishing. Spaapen et al. (2007) describe research in the interdisciplinary environments a "social process of knowledge production". 
Klein (2008: 119) comments that "Intellectual integration is leveraged socially". Although true of all research, and of disciplinary communities as well as interdisciplinary, the social shape and function is especially important in the latter. The aspect that this project illuminates at greatest intensity, remarked in other studies as an essential product of good research leadership, is the allocation of much greater resources of time in mutual interaction around the objects of study (in this case, the texts) (Defila and DiGiulio, 1999). Creating and sustaining the culture. The Ordered Universe has a regular core team of researchers, but also welcomes new participants each time we address a new treatise. New participants bring fresh perspectives and re-invigorate responses to the material. Both old and new participants benefit from the reminder of the radical commitment to common thinking, to extend from disciplinary lines to interdisciplinary results. Having created a culture of mutual listening, it is vital that it should be sustained and challenged. Slipping into routines is the first step towards a more complacent attitude towards the collaborative reading and the point at which participants stop listening to the research group around them, and, perhaps more problematically, to the thinkers and of ideas of the past that we encounter. Both Gray (2008), and McLeish and Strang (2014) have implicitly formulated the responsibility of sustaining healthy interdisciplinary practice and community foundation in terms of qualities and type of leadership function. However, both urge a delocalized and enabling quality of leadership as most effective in the interdisciplinary context, rather than command or directive.

\section{Practice: collaborative publication}

The Ordered Universe produces from our collaborative reading sessions a wide variety of outputs. Shorter expositions of particular chapters have appeared as a result of Ordered Universe presentations at conferences, and as submissions to academic journals. These are both co- and individually authored. We do, in some cases co-write, in others we engage a more editorial process. The latter is especially the case in the main editions, translation and commentaries to emerge from the project. ${ }^{15}$ These involve upto 19 authors, and involve considerable activity in drafting, commenting and compiling, to produce a volume that reads with a single voice.

The production of these pieces demands different collaborative practices. As a result of the complexities of the texts examined, focused consideration of particular issues is required from individuals after the collaborative readings. In the several months between collaborative symposia writing, calculation, archival research and other disciplinary activities take place before the same text is revisited. Each text is read through at least twice, and frequently more often. Over the months, the outputs begin to crystallize out of the swirling interdisciplinary mix.

In pursuing the solutions to Grosseteste's understanding of natural phenomena other, unusual, publications have emerged. A wonderful and unexpected process of reciprocity arises from each study - at some point the science team realizes that there is a calculation, an experiment, a series of observations to collate, stimulated by the interdisciplinary textual work, but that speaks to new or current questions in contemporary science. For example, the work on Grosseteste's colour space applied to the rainbow required a detailed calculation of how spectral distributions at different scattering angles, from rain of different drop sizes and illuminated by sunlight at varying elevation, mapped into current psychophysical colour spaces. The result was an entirely new mapping of $3 \mathrm{D}$ perceptual colour space that contributes to a current unanswered question in visual colour perception, published in the Journal of the Optical Society of America (Smithson et al., 2014a). The uncanny impression that we are, in some sense, collaborating with a thirteenth century thinker is hard to throw off when this sort of thing happens time and again (Bower et al., 2014).

Furthermore, the circular, or more accurately spiral, of hermeneutic that this process embeds in the transgressive exchange of perspective between the science and humanities disciplines, suggests that same metaphor arises as an example of the new "topologies" of interdisciplinarity suggested by Callard and Fitzgerald (2015). The boundaries between disciplines, in so far as they can be identified in this project, take on a multilayered form, but in which the levels are connected through the hermeneutical process. However, although particularly sensitive to the potential for unspoken and underlying power structures, particularly between science and humanities, that these authors warn of, we do not recognize their "fantasy of mutuality" in this context, notwithstanding that it might arise in others (Callard and Fitzgerald, 2015: 98).

A third, and equally unanticipated, form of output flows from the communication of the project to the wider academic world and wider audiences. The Ordered Universe has captured public imagination and interest, for example, as part of the Cheltenham Science Festival. The project website and blog has acquired a global and extensive readership. ${ }^{16}$ It also provides a forum for reflection on all aspects of the research, from content to methodology, from all participants, from graduate students to those attending public events. Video record of public workshops and lectures, podcasts, our film of the medieval cosmos, and a growing collection of resources for study, are all made publicly available. A wider readership has led to commissions from New Scientist, Nature, Nature Physics and other web and print media (McLeish et al., 2014; Smithson et al., 2014b). Perhaps it is the apparent quirkiness of the project, possibly the mystery and magic of the medieval in the public mind, but it may be the element of surprise, almost humour, in the idea of Latinists and optical physicists pouring together over medieval vellum and entering a conceptual world at once different from and related to our own, and the radical interdisciplinarity of the very idea, that also creates its attractiveness.

\section{Creative collaboration}

Most recently, the project has attracted the attention and engagement of a number of partners working in the creative arts. Sculptor and artist Alexandra Carr has been working on a series of pieces drawing on the treatises examined so far. Collaboration with projectionist Ross Ashton for the Durham Lumiere Festival 2015 produced the sound and light show "World Machine" fusing research from the Ordered Universe with the galaxy-modelling project from Durham's Institute of Computational Cosmology. A second project with Ashton is the IRIS installation, which takes the work on the rainbow, colour and visual perception to create an interactive experience for the viewer. We are also working with the National Glass Centre, University of Sunderland, and glass artists Cate Watkinson and Colin Rennie to explore Grosseteste's treatises in glass sculpture. Filmmaker Alan Fentiman is also involved with the project to create a cinematic meditation using the treatise on colour as a script.

These collaborations follow a similar pattern to our academic meetings, and the artists are regularly invited to participate equally within the collaborative reading sessions. Meeting and working together provides explanation and context for the artists, and wider perspectives for the science and medieval teams. We do not operate with a theorized vision of creative engagement; the focus is, as always through the project, placed on the treatises as the beginning and the end of our reflections. 


\section{Conclusions}

For Bacon later in the thirteenth century, Grosseteste was admirable not merely for his facility in mathematics, but also for his capacity for learning and in particular for translating from one cultural field to another. When discussing the difficulties involved in translating scientific terminology from different languages, it was Bacon's view that Grosseteste was the most successful of recent exponents:

For it is fitting that the translator should know the science he wants to convey and that he should know two languages, that from which and that to which he translates. But no one knew the languages but Boethius of all the famous translators, and no one [knew] the science except lord Robert bishop of Lincoln, through the length of his life and his experience, and through his industry and diligence; and because he knew mathematics and optics, and [thus] could know all things; and at the same time he knew the languages well enough so that he could understand the saints and philosophers and ancient sages. (Bacon, 1859a: 91)

The acts of translation encountered within the Ordered Universe project are multiple, from Latin to English, to mathematics, across academic disciplines and to the creative sector. Translation of this order demands high-level skills, but, most importantly, relies on collaboration, communication and a high-level of humility. In terms of interdisciplinary research, this project in particular has reminded us all what it is to be a student, to learn within a framework and by pushing against the constraints of current and previous orthodoxies. As practitioners within a group, we experience the odd sensation of being both learners and teachers that gives the specific character to inter-disciplinary research of this nature. Activities that are often treated separately, often for practical convenience, have to be carried out simultaneously. We are all at one and the same time learners and mentors, the guides and the lost, the knowledgeable and the ignorant. It is a strange position in which to be; disconcerting and stimulating in equal measure.

Listening to each other is the key to this process. It is a task requiring a great deal of effort, patience, energy and humility to remain sufficiently open-minded to the material and its elucidation. The moment that a participant ceases to listen is the moment when he or she loses the point of anchorage for the inter-disciplinary experience and analysis. Ceasing to listen means a reversion to a disciplinary understanding of the question at stake. The participant may also end up as an autodidact. While there is nothing wrong, intrinsically, in seeking to master new subject areas, how it is carried out is, as in all learning strategies, the key to its efficacy. One of the most important facets of our interdisciplinary research is, in fact, and in some senses ironically, the preservation of disciplinary expertise. The research group educate and lead each other. Collectively, rather more so than individually, we master the material.

The project furnishes a rich world of illustration, practical critique of and reflection on the many discussions of interdisciplinary research at the level of meta-analysis. The commonly visited grounds of leadership, reflective practice, learning, and the frequent metaphors of territory and boundary, inform our reflection too. However, the detailed and deeply engaged methodology of this project, and the complex "topologies" of engagement constitute a critical example by which such general structures of collaboration can be explored and tested.

Working together creates an environment in which the insights of scientists enrich humanities' understanding of medieval thought. At the same time this environment enables modern scientists to engage with scientific thinking from previous centuries resulting in new work in their own domains. Together, we bring the medieval texts to life, emphasizing the longer narrative to the place of science in human culture, and the mutual importance of the past and the present. The ramifications of the project on the legacy that period has for the way we think today, and on how we can work creatively between and among disciplines from the humanities and sciences, moving from respectful conversation to intense collaboration, are both radical and illuminating. The conversation and collaboration rely utterly on reading between the lines and listening twice as much as we speak.

\section{Notes}

1 The phrase was not included as a genuine fragment of Epictetus in later nineteenth century critical edition (Schenkl, 1916). On Elizabeth Carter see Hawley (2004/2016), Harcstarck Myers (1990) and Clarke (2001, esp. c.2).

2 For metaphors of listening see Peltola and Saresma (2014) and Gammelgaard (1998)

3 For more about the project itself, see http://www.ordered-universe.com.

4 For a summary of Baur's life and scholarly achievements, see McEvoy (2003) and Grabmann (1941).

5 Modern critical editions exist of the treatises On the Sphere, On Comets, On the Super-celestial Motions (Panti, 2001) and of the De luce (Panti, 2011, 2013), in addition to the Ordered Universe edition of the De colore (Dinkova-Bruun et al., 2013)

6 Grosseteste's authorities for optical learning included the Optics and Catoprtics attributed to Euclid, the De aspectibus of Al-kindi, translated into Latin by Gerard of Cremona in the later twelfth century, the pseudo-Eculid De speculis translated into Latin at the same time, and the Meteorology of Aristotle, which existed in a number of Latin translations. He was unfamiliar with the work of Ptolemy and Alhazan. His observations on refraction have, as a result of these limited sources, been interpreted as original (Eastwood, 1967; Lindberg, 1976; Smith, 2014).

7 Translation is courtesy of Dr Sigbjørn Sønnesyn, and will be forthcoming in the Ordered Universe edition of the treatise.

8 The portion of the De iride found in this manuscript is in the form of a fragment from the second half of the fourteenth century.

9 There is a related ambiguity in the modern Portuguese usage of experimental.

10 The consonance between humanities and science, especially in terms of the process of inspiration, is stressed by Gould (2003).

11 The description of the four models that follows quotes from Rost.

12 Take for example Weinberg's (2015) recent defence of a linear and progressive approach to the history of science, which proposes explicitly the judgement of pas scientific thinking by modern standards. Weinberg's observation that 'some historians of science make a shibboleth of not referring to present scientific knowledge in studying the science of the past' (xiii), is well taken. The Ordered Universe project does so, however, not to 'clarify past science' as Weinberg (xiii), but as part of a more complete and collective effort to understand Grosseteste's description of the phe nomena he chooses to explore.

13 On the question of what constitutes adequacy in disciplinary knowledge to do high quality interdisciplinary work, see Repko and Szostak (2016, chapter 6).

14 This requirement has long been recognized in literature on interdisciplinary research It is, for example, emphasized in the so-called Klein and Newell (1997: 393-294) definition: 'IDS may be defined as a process of answering a question, solving a problem, or addressing a topic that is too broad or complex to be dealt with adequately by a single discipline or profession...IDS draws on disciplinary perspectives and integrates their insights into a more comprehensive perspective'. See also Newell (2001).

15 These will appear in a seven volume series from Oxford University Press: The Scientific Works of Robert Grosseteste: Editions, English Translations and Interdisciplinary Analysis.

16 The project website, http://www.ordered-universe.com, incorporates a regular and active blog as well as digital and video resources.

\section{References}

Bacon R (1859) Compendium studii philosophiae. In: Brewer JS (ed). Opera quaedamhactenus inedita. Longman, Green Longman and Roberts: London.

Bacon R (1859a) Opus tertium. In: Brewer JS (ed). Opera quaedamhactenus inedita. Longman, Green Longman and Roberts: London.

Bacon R (1897) In: Bridges JH (ed). Opus maius; 2 vols. Oxford University Press: Oxford.

Bartlett R ([1982] 2006) Gerald of Wales A Voice of the Middle Ages. Tempus: Stroud, UK. 
Bauer HH (1990) Barriers against interdisciplinarity: implications for studies of science, technology, and society STS. Science, Technology \& Human Values; 15 (1): 105-119.

Baur L ed. (1912) Die Philosophischen Werke des Robert Grosseteste, Bischofs von Lincoln. Aschendorff: Münster, Germany.

Bower RG, McLeish TCB, Tanner BK, Gasper GEM, Panti C, Lewis N et al (2014) A medieval multiverse: Mathematical modelling of the thirteenth century universe of Robert Grosseteste. Proceedings of the Royal Society A; 470: 20140025.

Callard F and Fitzgerald D (2015) Rethinking Interdisciplinarity Across the Social Sciences and Neurosciences. Palgrave MacMillan: New York.

Carter E (1758) All the Works of Epictetus; Translated by E. Carter. S. Richardson: London.

Clarke N (2001) Dr Johnson's Women. Hambledon: London.

Colish M (1997) Medieval Foundations of the Western Intellectual Tradition, 4001400. Yale University Press: New Haven, CT.

Crombie AC (1953) Robert Grosseteste and the Origins of Experimental Science 1100-1700. Oxford University Press: Oxford.

Defila R and DiGiulio A (1999) Evaluating transdisciplinary research. Panorama: Swiss National Science Foundation Newsletter; 1, 4-27, [online], <www.ikaoe .unibe.ch/forschung/ip/Specialissue.Pano.1.99.pdf, accessed 26 June 2016.

Dinkova-Bruun G et al (2013) The Dimensions of Colour, Robert Grosseteste's De colore. Pontifical Institute of Mediaeval Studies: Toronto, ON.

Eastwood B (1967) Grosseteste's “quantitative” law of refraction: A chapter in the history of non-experimental science. Journal of the History of Ideas; 28, 403-414.

Eastwood B (1968) Medieval empiricism: The case of Robert Grosseteste's optics. Speculum; 43, 306-321.

Gammelgaard J (1998) Metaphors of listening. The Scandinavian Psychoanalytical Review; 21 (2): 151-167.

Gewin V (2015) Recipe for a team. Nature; 523, 245-247.

Giovani Mdi (2013) Averroes and philosophy in muslim Spain In: Marenbon J (ed). The Oxford Handbook of Medieval Philosophy. Oxford University Press: Oxford, pp 106-29.

Goering JW (1995) When and where did grosseteste study theology In: McEvoy J (ed). Robert Grosseteste: New Perspectives on His Thought and Scholarship. Brepols: Turnhout, Belgium, pp 17-51.

Gould SJ (2003) The Hedgehog, the Fox, and the Magister's Pox. Vintage: London.

Grabmann M (1941) Ludwig Baur und die geschichtliche Erforschung der mittelalterlichen Philosophie. Ein Gedenkblatt zu seinem 70. Geburtstag. Philosophiches Jahrbuch; 54, 137-41.

Gray B (2008) Enhancing transdisciplinary research through collaborative leadership. American Journal of Preventive Medicine; 35 (2S): S124-S132.

Grosseteste R (1981) In: Rossi P (ed). Commentarius in Posteriorum Analyticorum libros. Olschki: Florence, Italy.

Harcstarck Myers S (1990) The Bluestocking Circle: Women, Friendship, and the Life of the Mind in Eighteenth-Century England. Oxford University Press: Oxford.

Hawley J ([2004] 2016) Carter, Elizabeth (1717-1806). In: Matthew HCG and Harrison B (eds). Oxford Dictionary of National Biography. OUP: Oxford.

Hoskins P (2015) Robert Grosseteste as Bishop of Lincoln: The Episcopal Rolls 1235-1253. Boydell and Brewer for the Lincoln Record Society: Woodbridge, ON.

Klein JT (2008) Evaluation of interdisciplinary and transdisciplinary research-A literature review. American Journal of Preventative Medicine; 35 (2)Supplement S116-S123.

Klein JT and Newell WH (1997) Advancing interdisciplinary studies. In: Gaff J and Ratcliff J (eds). Handbook of the Undergraduate Curriculum. Jossey-Bass: San Francisco, CA, pp 393-415.

Koyré A (1957) The origins of modern science: A new interpretation. Diogène; $17,1-22$.

Lash N (1996) Contemplation, metaphor and real knowledge. In: Lash N (ed). The Beginning and End of Religion. Cambridge University Press: Cambridge, pp 112-131.

Lindberg D (1976) Theories of Vision from Al-kindi to Kepler. Chicago University Press: Chicago, IL.

McEvoy J (2000) Robert Grosseteste. Oxford University Press: Oxford.

McEvoy J (2003) Robertus Grossatesta Lincolniensis: An essay in historiography medieval and modern. In: O'Carroll M (ed). Robert Grosseteste and the Beginnings of a British Theological Tradition. Bibliotheca SeraphicoCappuccina: Rome, Italy, pp 21-99.

McLeish TCB and Poon WCK (2001) How many cultures? "Real presences" and the healing of the academy. Interdisciplinary Science Review; 26, 167-172.

McLeish et al (2014) A medieval multiverse? Nature; 507, 161-163.

McLeish TCB and Strang V (2014) Leading interdisciplinary research: Transforming the academic landscape, Stimulus Paper, The Leadership Foundation for Higher Education, http://www.lfhe.ac.uk/en/research-resources/publica tions/index.cfm/ST-28, accessed 26 June 2016.
McLeish TCB and Strang V (2015) Evaluating Interdisciplinary Research: A Practical Guide. Durham University Institute of Advanced Studies: Durham, UK.

Newell WH (2001) A theory of interdisciplinary studies. Issues In Integrative Studies; 19, 1-25.

Newton I (1669) Lectiones opticae, http://www.newtonproject.sussex.ac.uk/view/ texts/diplomatic/NATP00306, accessed 24 February 2016.

Osborne T (2013) Inter that discipline! In: Barry A and Born G (eds). Interdisciplinarity: Reconfigurations of the Social and Natural Sciences. Routledge: London, pp 82-98.

Panti C (1998) Robert Grosseteste's theory of sound. In: Hentschel F (ed). Musik und die Geschichte der Philosophie und Naturwissenschaften im Mittelalter; Studien und Texte zur Geistesgeschichte des Mittelalters, 62 Brill: Leiden, The Netherlands; Boston, MA; Köln, Germany, pp 3-17.

Panti C (2001) Moti, virtù e motori celesti nella cosmologia di Roberto Grossatesta. Studio ed edizione dei trattati "De sphera», "De cometis», "De motu supercelestium». Sismel -Edizioni del Galluzzo: Firenze, Italy.

Panti C (2011) Roberto Grossatesta, La Luce. Edizioni Plus-Pisa University Press: Pisa, Italy.

Panti C (2013) Robert Grosseteste's De luce: A critical edition. In: Flood JR, Ginther and Goering JW (eds). Robert Grosseteste and His Intellectual Milieu. Pontifical Institute of Mediaeval Studies: Toronto, ON, pp 193-238.

Peltola H-R and Saresma T (2014) Spatial and bodily metaphors in narrating the experience of listening to sad music. Musicae Scientiae; 18 (3): 292-306.

Repko AF and Szostak R (2016) Interdisciplinary Research: Process and Theory, 3rd ed., Sage: New York, pp 146-179.

Rost M (2002) Teaching and Researching Listening. Pearson Education: Harlow, UK.

Schenkl H (1916) Epicteti Dissertationes ab Arriano Digestae, 2nd ed., Teubner: Leizig, Germany.

Smith AM (2014) From Sight to Light: The Passage from Ancient to Modern Optics. Chicago University Press: Chicago, IL.

Smithson HE, Dinkova-Bruun G, Gasper GEM, Huxtable MJ, McLeish TCB and Panti C (2012) A three-dimensional color space from the 13th century. Journal of the Optical Society of America (A); 29 (2): A346-A352.

Smithson HE, McLeish TCB, Anderson P, Gasper GEM, Panti C et al (2014a) Color-coordinate system from a 13th-century account of rainbows. Journal of the Optical Society of America; 31, A341-A349.

Smithson HE, McLeish TCB and Gasper GEM (2014b) All the colours of the rainbow. Nature Physics; 10 (4), 540-542.

Smithson HE (2015) Perceptual organization of colour. In: Wagemans J (ed) Oxford Handbook of Perceptual Organization. Oxford University Press: Oxford, pp 436-465.

Snow CP (1959) The Two Cultures. Cambridge University Press: Cambridge.

Southern RW (1992) Robert Grosseteste: The Growth of an English Mind in Medieval Europe, 2nd ed., Oxford University Press: Oxford.

Spaapen J, Dijstelbloem H and Wamlink F (2007) Evaluating Research in Context: A Method for Assessment, 2nd ed., Consultative Committee of Sector Councils for Research and Development: The Hague, Netherlands.

Thompson C (2005) Making Parents: The Ontological Choreography of Reproductive Technologies. MIT Press: Cambridge, MA

Walsh M (2010) Theories of text, editorial theory and textual criticism. In: Saurez SJ MF and Wouldhuysen HR (eds). The Oxford Companion to the Book; Vol. 1 Oxford University Press: Oxford, pp 156-163.

Weinberg S (2015) To Explain the World: The Discovery of Modern Science. Harper Collins: New York.

Woods A (2015) . .Interdisciplinary Authorship. Working Knowledge: Transferable Methodology for Interdisciplinary Research. [online], http://www.workingknowl edgeps.com/wp-content/uploads/2015/02/WK_Interd_Auth_FINAL.pdf, accessed 26 June 2016.

Wooton D (2015) The Invention of Science: A New History of the Scientific Revolution. Penguin: London.

\section{Data availability}

Data sharing not applicable to this article as no datasets were generated during the current study. Any analysed data, and their sources, are indicated in the text.

\section{Acknowledgements}

The authors are extremely grateful in what follows to comments and input from Dr Rachael Matthews, Professor Brian Tanner and Dr Sigbjørn Sønnesyn, and to the whole Ordered Universe research team whose collective efforts over the past 6 years we have drawn on and attempted to represent.

\section{Additional information}

Competing interests: The authors declare no competing financial interests. 
Reprints and permission information is available at http://www.palgrave-journals.com/ $\mathrm{pal} /$ authors/rights_and_permissions.html

How to cite this article: Gasper G et al. (2016) Listening between the lines: medieval and modern science. Palgrave Communications. 2:16062 doi: 10.1057/palcomms.2016.62. (c) (i) This work is licensed under a Creative Commons Attribution 4.0 cc) International License. The images or other third party material in this article are included in the article's Creative Commons license, unless indicated otherwise in the credit line; if the material is not included under the Creative Commons license, users will need to obtain permission from the license holder to reproduce the material. To view a copy of this license, visit http://creativecommons.org/licenses/by/4.0/ 